\title{
The role of essential fatty acids and prostaglandins
}

\author{
M. A. Crawford \\ B.Sc., Ph.D. \\ The Zoological Society of London, Nuffield Laboratories of Comparative Medicine, \\ Institute of Zoology, Regent's Park, London NWI 4RY
}

\begin{abstract}
Summary
The FAO/WHO Rome Report recommended an increase in the consumption of fat in countries where malnutrition is endemic; for maintenance, $3 \%$ of the dietary energy as essential fatty acids (EFA) may be adequate; in pregnancy and lactation an additional 1.5 to $2.4 \%$ energy as EFA is needed. For populations at high risk for atherosclerosis and coronary heart disease (CHD) the recommendations were to decrease saturated fat in particular and increase EFA intake in the diet, reduce sugar, alcohol and cholesterol. These recommendations were similar to those of the Royal College of Physicians but the report went further by saying that EFA loss through industrial hydrogenation should be minimized and associated nutrients such as vitamin $E$ and carotene should be restored if lost in processing. In terms of production, they asked for an increase in edible plant oils in developing countries and requested that intensive animal feeding and breeding should be corrected to avoid the excess accumulation of saturated fats. In addition, the Rome Report requested meaningful labelling of amounts and quality of fat in foods containing added fats.

The basic aims of the Report were to state the position of lipid nutrition. The issue of the nutrient correction in terms of CHD cannot properly be discussed without taking into account the essential components which are needed for the integrity and development of the vascular system.
\end{abstract}

\section{Introduction}

In 1977 an expert consultation was called by the WHO and the FAO in Rome, to discuss the role of dietary fats in human nutrition (FAO/WHO, 1978). A principal reason for the committee was the omission of the question of essential fatty acids (EFAs) by most previous medical and scientific reports. The debate on diet and heart disease had concerned those nutrients or those components of the diet which in a nutritional context are not essential, i.e. saturated fats, cholesterol, sugar and triglyerides. However, the omission of EFAs was obvious by 1975/1976, when the FAO/WHO arranged the expert consultation on dietary fats. It did not really make sense to discuss coronary heart disease and nutrition whilst omitting those nutrients essential for the growth and development of the vascular system and which are implicated in the regulation of platelet aggregation and thrombosis.

Some of the main points of the FAO/WHO Rome Report (FAO/WHO, 1978) will now be reviewed, especially those dealing with EFAs, and recent developments will be introduced. The Rome Report contains over 250 references and only some recent and key papers will be noted in this paper. The report included the following chapters: (1) Definitions; (2) Fat as a source of energy; (3) Use of fat in adult and child feeding; (4) Essential fatty acids; (5) Cardiovascular disease; (6) Processing; (7) Special considerations (such as erucic acid); (8) Plant and animal breeding and management and its effect on food quality and quantity.

\section{Definitions}

There are 2 different types of fat in the body:

(2) Storage, or adipose, fat which provides a source of energy, is mainly triglyceride and is variable in response to diet.

(2) Structural lipid which contains phosphoglycerides and cholesterol. Phosphoglycerides are resistant to change in response to diet. A high proportion $(30-40 \%)$ of the fatty acids in the phosphoglycerides are essential for reproduction, growth and the integrity of cell membranes. The essential fatty acids (EFA) in the lipids are analogous to the essential amino acids of proteins. Quantitatively the structural fats are the most important structural component in the brain and the second most important in all other soft tissues.

\section{Fat as a source of energy}

In developing countries, about $70 \%$ of malnutrition is thought to result from an inadequate amount of dietary energy, mainly because of a low energy density in the diet. As fat has the highest proportion of calories per unit weight of all foods, it is possible under these particular circumstances that fat itself 
could be an important or possibly an 'essential component' of the diet.

The conclusion reached in Rome was that, in developing countries with a high incidence of malnutrition, the fat intake should be increased. If that is to be done, then one needs to ask the question 'What type of fat?'. This was another reason why FAO were particularly interested in the subject of fat quality and its fatty acid composition.

\section{Fat in pregnancy}

Fat provides an important source of dietary and metabolic energy in pregnancy, lactation and in early infant development. If the data from Aberdeen, for the accumulation of nutrient compartments during pregnancy, are plotted as velocities, one sees that fetal growth does not really commence until the 26th or 27th week of pregnancy when it accelerates rapidly (Hytten and Leicht, 1971). Before this phase of fetal growth, there is a deposition of very substantial amounts of fat in the pregnant mother. This fat can be used as an energy store especially at the time when a volume restriction on food intake results from the expansion of the uterus, placenta, fetus and blood volume, and could mitigate against simultaneously increasing food intake to maintain pace with the acceleration of fetal growth. Fat appears to play an important part in the energy economy in pregnancy and also in providing for the initiation of successful lactation; one third of the cost of energy of lactation over the first 100 days can be provided by the fat store (WHO Expert Committee, 1964). This store not only provides energy for fetal growth and lactation but will also donate EFAs. It is the consideration of EFA content of the fat stores that raises the qualitative question on dietary fats.
Essential fatty acids

EFAs are those fatty acids which are required by biological systems for reproduction and growth (Burr and Burr, 1930). Two essential fatty acids occur in plants; linoleic (C18:2,n-6) and $\alpha-$ linolenic $(\mathrm{C} 18: 3, \mathrm{n}-3)$. The main source of the two EFAs in plants occurs in a complementary distribution pattern: seeds in general, have relatively high proportions of linoleic acid in their oils, whereas green leaves have relatively high proportions of $\alpha$ linolenic acid in their tissue lipids. The chain elongation and desaturation process is illustrated below (Fig. 1).

The essential fatty acids have double bonds close to the methyl end (n-6 or n-3) of the molecule in positions in which animals cannot insert double bonds. The number of double bonds in the molecule is proportional to the degree of liquidity. Animals, somewhat simplistically (but none the less relevant), have higher 'liquidity' requirements than do plants; 7 they operate at $37^{\circ} \mathrm{C}$, their transport mechanisms 을 operate at faster rates, and they move about. Animals achieve higher degrees of biological liquidity in their tissue lipids by adding more double bonds and by chain elongation at the carboxyl end of the molecule; this metabolic process $\vec{c}$ produces the long chain, highly unsaturated deriva tives. It is these long chain derivatives which are mainly used in cell membranes and are the pres cursors of prostaglandins (PGs).

\section{Competition between saturated fats and EFAs}

The same enzyme systems handle all fatty acids of similar chain lengths to the EFAs. This means that if there are large amounts of non-essential saturated fatty acids, they will compete with the essential fatty acids and suppress their activity. This effect has been

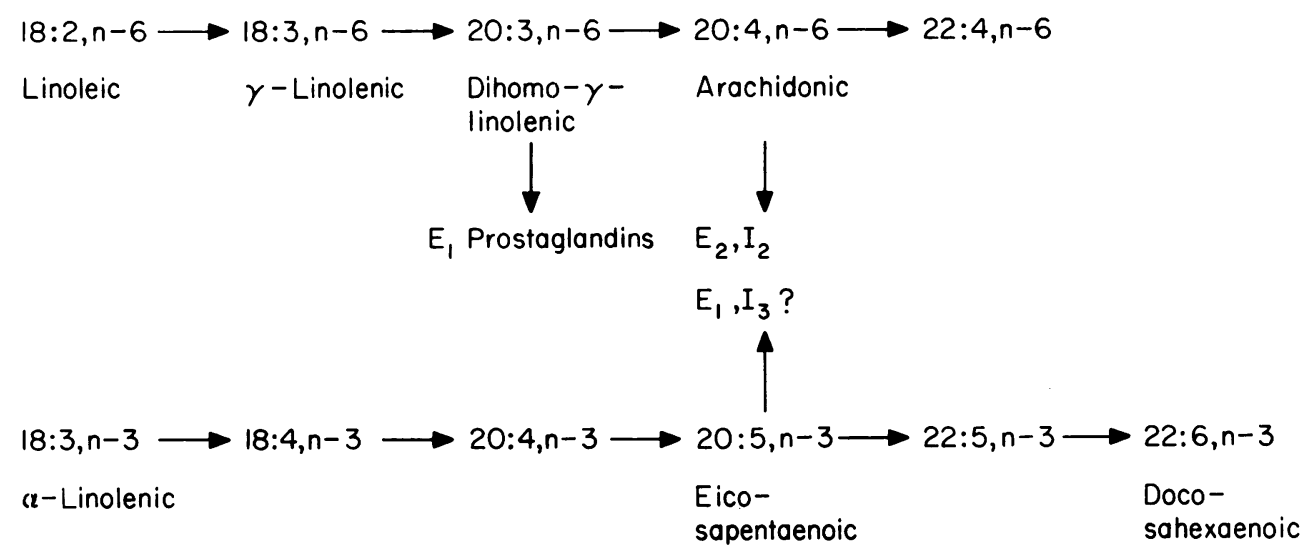

FIG. 1. Desaturation and chain elongation of the essential fatty acids. 
illustrated in studies in which EFA deficiency is exacerbated by simultaneously feeding saturated fat (Burr and Burr, 1930).

The long chain derivatives of linoleic and $\alpha$ linolenic acids are the precursors of PGs and major constituents of cell membranes (Van Dorp et al., 1964; Bergstrom, Danielsson and Samuelson, 1964). Consequently, the rate of desaturation and chain elongation will be an important determinant of biological activity. The rate of conversion of linoleic acid to the PG precursors is slow in all animals studied (Marcel, Christiansen and Holman, 1968; Hassam, Rivers and Crawford, 1977). Desaturation is dependent on zinc and copper and the rate of reaction is greater under the influence of female sex hormones. This latter effect may explain why male animals are more susceptible than females to EFA deficiency and the influence of saturated fats.

\section{Dietary link with prostaglandin synthesis}

In addition to their structural function, EFAs act as 'regulators' at very low concentrations via their PG derivatives. Prostaglandins control platelet adhesion and aggregation, regulate smooth muscle and vascular tone and may consequently be involved in control of BP and thrombus formation.

It was originally thought that all PGs were derived from phospholipids which were built into cell membranes (Willis and Stone, 1974). However, there is now increasing evidence that they are also derived directly from dietary linoleic acid intake (Hassam et al. (1979) via the 'metabolic pool'. Willis et al. (1974) showed that eicosatrienoic acid (20:3, $n-6)$, is converted to prostaglandin $E_{1}$ which, before the discovery of prostacyclin, was the most active suppressor of platelet aggregation. $P G_{1}$ can be synthesized directly from the metabolic pool, preventing platelet aggregation in the body of the circulation.

Arachidonic acid (20:4, n-6) gives rise to prostacyclin (Moncada et al., 1976) which has the interesting property of preventing platelets from adhering to the vascular endothelium. Arachidonic acid is also the precursor of prostaglandin $\mathrm{E}_{2}$ and the thromboxanes that precipitate aggregation.

If endothelial damage occurs, as in trauma, lipases are released and hydrolyse the phospholipids from which relatively large amounts of arachidonic acid (Table 1) are liberated (arachidonic acid is the major fatty acid component of these cell membrane phospholipids). The free arachidonic acid is then converted to $\mathrm{PGE}_{2}$ and its thromboxane derivatives, leading to thrombus formation which in the case of trauma is needed for repair (Fig. 2).

The metabolic pool offers a direct link between prostaglandin synthesis and the dietary intake of the precursors (Fig. 2). In experiments in which rabbits were fed EFA deficient diets it was found that arachidonic acid in the membranes did not fall over a period of 4-8 weeks, but $P E_{1}, E_{2}$ and $F_{2} \alpha$ were depressed in the brain, liver, lung and eye (Hassam et al., 1979). These experiments indicate a direct metabolic link between precursor and these endogenous PGs rather than a membrane source. Indeed, the evidence of PG activity in response to an increased linoleic acid intake appears too rapidly to be explained by alterations in membrane bound precursors as these require many weeks before chagen in composition can be affected by diet.

TABLE 1. Essential fatty acid component of human endothelial phosphoglycerides from eleven post-mortem aorta samples from males (25-45 years old)

\begin{tabular}{|c|c|c|}
\hline Fatty acid & $\begin{array}{c}\text { Ethanolamine } \\
\text { phosphoglyceride }\end{array}$ & $\begin{array}{c}\text { Choline } \\
\text { phosphoglyceride }\end{array}$ \\
\hline $\begin{array}{l}18: 2 \mathrm{n}-6 \\
20: 3 \mathrm{n}-6 \\
20: 4 \mathrm{n}-6 \\
22: 4 \mathrm{n}-6 \\
22: 5 \mathrm{n}-6 \\
18: 3 \mathrm{n}-3 \\
20: 5 \mathrm{n}-3 \\
22: 5 \mathrm{n}-3 \\
22: 6 \mathrm{n}-3\end{array}$ & $\begin{array}{r}4.2(0.6) \\
0.9(0.2) \\
22.0(2.1) \\
5.7(0.5) \\
1.8(0.4) \\
0.8(0.3) \\
1.6(0.5) \\
4.2(0.8) \\
9.7(1.0)\end{array}$ & $\begin{array}{r}17.0(2.0) \\
2.8(0.9) \\
10.0(0.8) \\
2.2(0.4) \\
0.4(0.1) \\
0.9(0.2) \\
1.0(0.3) \\
1.8(0.4) \\
2.6(0.4)\end{array}$ \\
\hline
\end{tabular}

Data expressed as fatty acid in $\mathrm{g} / 100 \mathrm{~g}$ of phospholipid fatty acids (s.e.), $\mathrm{n}=\mathbf{8}$.

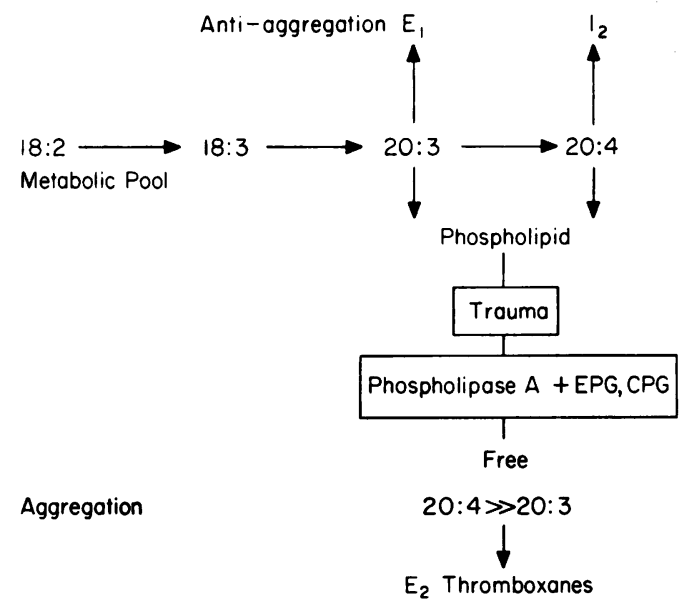

Fig. 2. Diagram of the suggested mechanisms of atherosclerosis and of coronary thrombosis.

\section{Early development}

Brain development occurs early in the life cycle and illustrates the concept of the "critical period of growth' (Dobbing, 1972). The time at which changes in tissue development are most easily imposed by nutritional means is during rapid growth of the 
tissue. Experiments show that a nutritional insult to the brain during its vulnerable period results in defects which may be permanent (Sinclair and Crawford, 1973).

The brain is predominantly built during the first 1-4 years of life, and the EFAs used in brain cell membrane are exclusively restricted to the long chain derivatives. Therefore, conversion of linoleic and $\alpha$-linolenic acids to their long chain derivatives is an important consideration. It has been shown in vivo (Galli et al., 1977) and in vitro (Brenner, $1969)$ that the rate of the first $(\Delta 6)$ desaturation is particularly slow, so the question arises as to how the brain accumulates such high concentrations of polyunsaturated FAs. The answer is 'by biomagnification'. The maternal liver first desaturates a small proportion of the dietary EFA, the end result is re-processed by the placenta, then by the fetal liver and finally by the fetal brain (Crawford $e t$ al., 1976a, b).

Relatively high concentrations of arachidonic acid are stored in the placenta to pass on to the fetus

TABLE 2. Choline phosphoglycerides at term. Mean $\%$ of fatty acid and (s.e.) $n=19$

\begin{tabular}{lccc}
\hline Fatty acid & $\begin{array}{c}\text { Maternal } \\
\text { plasma }\end{array}$ & Placenta & $\begin{array}{c}\text { Cord } \\
\text { plasma }\end{array}$ \\
\hline $\begin{array}{l}\text { Linoleic } \\
18: 2, \mathrm{n}-6\end{array}$ & $22.0(1 \cdot 2)$ & $10.5(0 \cdot 6)$ & $9.6(0 \cdot 9)$ \\
$\begin{array}{l}\text { Dihomo } \gamma- \\
\text { Linolenic } \\
20: 3, \mathrm{n}-6\end{array}$ & $2 \cdot 8(0 \cdot 2)$ & $5 \cdot 1(0 \cdot 2)$ & $5 \cdot 8(0 \cdot 3)$ \\
$\begin{array}{l}\text { Arachidonic } \\
20: 4, \mathrm{n}-6\end{array}$ & $9.9(0 \cdot 9)$ & $23.0(0 \cdot 7)$ & $16.0(0 \cdot 8)$ \\
\hline
\end{tabular}

(Table 2). These facts pose a question to the curious claims that polyunsaturates are dangerous! If polyunsaturates are dangerous, why are they accumulated in such high density in the placenta to be passed on to the fetus?

\section{Relevance of EFA to the vascular system}

Firstly, the growth and development of the vascular system takes place during childhood (Fig. 2 ). Secondly, the growth of the vascular system is not a linear development but a surface area or, more accurately, a cylindrical function. The vascular system is growing at a rate which will be proportional to between the square and cube of the increase in body growth as measured by the increase in height, i.e. nutritional considerations concerning the development of the vascular system are likely to be weightier than would appear if only the body growth of the child was considered.

Experimental studies which attempted to reproduce atherosclerosis in experimental animals have, in general used young, growing animals and the nutritional approach of feeding non-essential fatty acids or other non-essential fatty components in the diet.

Large amounts of saturated fats or cholesterol in the diet produced an EFA-deficiency situation. This point has been missed by previous workers who were not thinking in terms of the EFA components needed for PGs and integrity of the vascular wall. In other words, previous experiments on dietinduced atherosclerosis have been models for EFA deficiency as well as testing saturated fats. This re-evaluation of the literature on experimentad atherosclerosis is particularly important when it is remembered that EFA activity is suppressed be feeding saturated fats.

\section{Human requirements for EFA}

Analysis of the EFA composition of human milk in different countries (e.g. United Kingdom and Tanzania) shows a remarkable similarity (Table 3 ) in milk EFA content which averaged about $6 \%$ of the milk energy. This is the same as the component of dietary energy for protein, therefore the balance of EFA to protein is a one-to-one relationship in the natural diet of the infant.

Such data were used by the Rome Committee to estimate the requirements for lactation and pregnancy. Milk secretion involves a loss of EFAs, the amount of which can be determined by analysis, and the exact minimum which must be replaced to maintain the mother in balance can be calculated

TABle 3. Fatty acids (mean) in milk samples from 7 countries

\begin{tabular}{lccccccc}
\hline Fatty acids & U.K. & Denmark & Uganda & Tanzania & Saudi Arabia & Finland & Sri Lanka \\
\hline 10 & $0 \cdot 8$ & 0.9 & $2 \cdot 8$ & 3.4 & $\sim$ & 0.8 & $5 \cdot 3$ \\
12 & $3 \cdot 7$ & $4 \cdot 2$ & $9 \cdot 4$ & 10 & $2 \cdot 6$ & $6 \cdot 6$ & 12 \\
14 & $8 \cdot 9$ & $7 \cdot 5$ & 14 & 13 & $6 \cdot 1$ & $9 \cdot 1$ & 13 \\
16 & $24 \cdot 5$ & $24 \cdot 8$ & 24 & 25 & $27 \cdot 1$ & $27 \cdot 9$ & 26 \\
$18: 0$ & $8 \cdot 6$ & $8 \cdot 6$ & $4 \cdot 7$ & $4 \cdot 2$ & $5 \cdot 8$ & $7 \cdot 8$ & $5 \cdot 3$ \\
$18: 1$ & 36 & $32 \cdot 5$ & 29 & 28 & $36 \cdot 1$ & $33 \cdot 1$ & 26 \\
$18: 2$ & $8 \cdot 2$ & $12 \cdot 3$ & $9 \cdot 7$ & 10 & 12 & $8 \cdot 9$ & $6 \cdot 3$ \\
$18: 3$ & $0 \cdot 7$ & $1 \cdot 2$ & $1 \cdot 1$ & 0.8 & $0 \cdot 4$ & 0.8 & $0 \cdot 7$ \\
$n=$ & 116 & 33 & 38 & 67 & 14 & 5 & 18 \\
\hline
\end{tabular}


TABLE 4. Essential fatty acids (EFA) (g/day) in milk at 2 different energy levels

\begin{tabular}{|c|c|c|c|}
\hline Fatty acid & $\begin{array}{c}\text { Energy as } \\
\text { total EFA } \\
\text { in milk }\end{array}$ & $\begin{array}{l}\text { g/day ir } \\
600 \mathrm{kcal} \\
(2 \cdot 5 \mathrm{MJ})\end{array}$ & $\begin{array}{l}\text { milk of } \\
810 \mathrm{kcal} \\
(3.4 \mathrm{MJ})^{1}\end{array}$ \\
\hline $\begin{array}{l}\text { Linoleic acid } \\
18: 2, \mathrm{n}-6\end{array}$ & $\begin{array}{l}6 \\
4\end{array}$ & $\begin{array}{l}3 \cdot 0 \\
2 \cdot 0\end{array}$ & $\begin{array}{l}4 \cdot 0 \\
2 \cdot 7\end{array}$ \\
\hline $\begin{array}{l}\text { Alpha-linolenic } \\
18: 3, \mathrm{n}-3\end{array}$ & $\begin{array}{l}6 \\
4\end{array}$ & $\begin{array}{l}0 \cdot 26 \\
0 \cdot 18\end{array}$ & $\begin{array}{l}0 \cdot 35 \\
0 \cdot 23\end{array}$ \\
\hline $\begin{array}{l}\text { Long-chain }{ }^{2} \\
\text { EFA n-6 }\end{array}$ & $\begin{array}{l}6 \\
4\end{array}$ & $\begin{array}{l}0 \cdot 19 \\
0 \cdot 16\end{array}$ & $\begin{array}{l}0.25 \\
0 \cdot 21\end{array}$ \\
\hline $\begin{array}{l}\text { Long-chain }{ }^{2} \\
\text { EFA n-3 }\end{array}$ & $\begin{array}{l}6 \\
4\end{array}$ & $\begin{array}{l}0 \cdot 28 \\
0 \cdot 19\end{array}$ & $\begin{array}{l}0 \cdot 38 \\
0 \cdot 25\end{array}$ \\
\hline
\end{tabular}

$1810 \mathrm{kcal}(3.4 \mathrm{MJ})$ is the mean value of the range for energy requirements from the age of 3 months onwards.

${ }^{2}$ Total long-chain essential fatty acids taken as 0.68 energy per cent. for the later period of lactation.

(Taken from FAO/WHO Joint Report, 1977 (1978) Dietary Fats and Oils in Human Nutrition. FAO Technical Papers Series, No. 3, Rome.)

(Table 4). Calculation of the amount of milk and its content of EFA yields an estimate of $5-7 \%$ of the energy as EFA in lactation and about $4.5 \%$ during pregnancy in order to maintain the mother in balance.

\section{CHD risk factors during vulnerable infant develop-} ment

\section{Blood EFA}

Comparison of infants fed on cow's or human milk has shown that the long chain EFA components (which represent the stores of EFA) fall from relatively high concentrations associated with fetal development (Pikaar and Fernandes, 1966; Sanders and Naismith, 1976; Crawford, Hassam and Hall, 1976a) to adult values over a 4- to 6-month period, in breast-fed infants, but fall to below adult values in 4 weeks in the cow's milk-fed infants (Table 5).

\section{Blood cholesterol and hypertension}

A second relevant feature emerges from studies of lipids in children. Comparison of the blood lipids of children in the high CHD risk group compared to low risk African groups has demonstrated that the high risk group can be identified by the rise in blood cholesterol at the age of 6-8 years (Du Plessis, Vivier and DeLange, 1967; Crawford, Hassam and Rivers, 1978; De Haas, 1978). Similarly, in children in high risk communities, it has been found that rise in BP begins in the same age group (Lauer, Rames and Clarke, 1978).

\section{Plant and animal breeding}

In general, seed oils are rich in linoleic acid (Table 6). It is possible now to alter the composition of plant fatty acids. It was discovered that erucic acid, present in rape seed oil, appeared to cause cardiomyopathy in rats. A new kind of rape seed was bred which is comparatively low in erucic acid (FAO/WHO, 1978).

Free-living animals reared under conditions where they are left to select their own food provide a meat-fat rich in polyunsaturates. This is logical because meat is muscle tissue and is rich in cell membranes, mitochondria and other cell structures with component EFAs. Increased use of intensive feeding systems over the last 2 centuries has led to an increase in adipose fat deposition which has inevitably caused a reduction between the balance of saturated fats and essential fatty acids. In meat from wild bovids, about one third of the fatty acids were found to be EFA or polyunsaturated; in domestic animals only one fifth of the fatty acids were EFA (Crawford et al., 1970). Two principle factors produced this striking difference: the first, the amount of saturated fat was increased in domestic animals through (a) restriction of exercise, (b) use of high energy foods, (c) genetic selection for the fast growing animal; the second, the increase of adipose fat led to intramuscular infiltration of triglyceride (called 'marbleing' in the livestock industry). This triglyceride is mainly composed of non-essential fatty acids and its infiltration further increases the amount of saturated fats and also reduces the nutrient value per unit of meat weight. The infiltration of triglyceride replaces muscle cells which means a reduction in protein, minerals, trace elements, vitamins and EFAs. In summary, intensification of animal management has resulted both

TABLE 5. Triglyceride levels of 6 and 3 long-chain polyunsaturated fatty acids (LCP) in breast- and bottle-fed infants

\begin{tabular}{lllcccc}
\hline & & & \multicolumn{3}{c}{ g/100 Fatty acid methyl esters } \\
& & Milk & Week 1 & Week 6 & Week 18 & Adult \\
\hline n-6 & LCP & Human $(n=10)$ & 4.5 & $2 \cdot 2$ & $1 \cdot 7$ & 0.52 \\
& & Cow $(n=12)$ & $4 \cdot 3$ & 1.0 & 0.20 & \\
n-3 & LCP & Human $(n=10)$ & 3.8 & 2.5 & 1.0 & 0.44 \\
& Cow $(n=12)$ & 3.4 & 0.91 & 0.13 & \\
\hline
\end{tabular}


in an increase in the amount of saturated fat and a reduction in the amount of EFA per unit of meat eaten.

The Rome Report recommended that we should correct what was seen as a wrong direction in the rearing of animals; it was thought that animals should once again be bred for meat and not fat.

\section{References}

Bergstrom, S., Danielsson, H. \& Samuelson, B. (1964) The enzymatic formation of prostaglandin E2 from arachidonic acid. Biochimica et biophysica acta, 90, 207.

BRENNER, R.R. (1969) Reciprocal interactions in the desaturation of linoleic acid into y-linolenic and eicosa-8, 11, 14-trienoic into arachidonic. Lipids, 4, 621.

Burr, G.O. \& Burr, M.M. (1930) A new deficiency disease produced by the rigid exclusion of fat from the diet. Journal of Biological Chemistry, 86, 587.

Crawford, M.A., Gale, M.M., Woodford, M.H. \& CASPERD, N.M. (1970) Comparative studies on fatty acid composition of wild and domestic meats. International Journal of Biochemistry, 1, 295.

Crawford, M.A., Hassam, A.G. \& Hall, B.M. (1976a) Metabolism of essential fatty acids in the human fetus and neonate. Nutrition Metabolism. 21, 17.

Crawford, M.A., Hassam, A.G. \& Ribers, J.P.W. (1978) Essential fatty acids and the vulnerability of the artery during growth. Postgraduate Medical Journal, 54, 137.

Crawford, M.A., Hassam, A.G., Williams, G. \& WhiteHOUSE, W.L. (1976b) Essential fatty acids and fetal brain growth. Lancet, i, 452.

DE HAAS, J.H. (1978) Risk factors of CHD in children-a retrospective view of the Westland study. Postgraduate Medical Journal, 54, 187.

DobBING, J. (1972) Vulnerable periods of brain development. In: Lipids Malnutrition and the Developing Brain (Ed by Elliot, K. and Knight, J.), p. 9. Amsterdam Associated Scientific Publishers.

Du Plessis, J.P., Vivier, F.S. \& De Lange, D.J. (1967) The biochemical evaluation of the nutritional status of urban school children aged 7-15 years serum cholesterol and phospholipid levels and serum and urinary amylase activities. South African Medical Journal, 41, 1216.

FAO/WHO JOINT RePORT, 1977 (1978) Dietary Fats and Oils in Human Nutrition. The FAO Technical Papers Series No. 3, Rome.
Galli, C., Galli, G., Spagnuolo, C., Bosisio, E., Tosi, L., Folco, G.C. \& Longiave, D. (1977) In: Function and Biosynthesis of Lipids. (Edited by Bazan, N.G., Brenner, R.R. \& Giusto, N.M.), p. 561. Plenum Press, New York.

Hassam, A.G., Rivers, J.P.W. \& Crawford, M.A. (1977) Metabolism of gamma-linolenic acid in essential fatty acid-deficient rats. Journal of Nutrition, 107, 519.

Hassam, A.G., Willis, A.L., Denton, J.P., Stevens, P. \& CRAWFORD, M.A. (1979) The effect of essential fatty acid deficient diet on the levels of prostaglandins and their fatty acid precursors in the rabbit brain. Lipids, 14, 78.

Hytten, P.E. \& Leicht, I. (1971) The Physiology of Human Pregnancy. Blackwell Scientific Publications, Oxford.

Lauer, R.M., Clarke, W.R. \& Rames, L.K. (1978) Blood pressure and its significance in childhood. Postgraduate Medical Journal, 54, 206.

Marcel, Y.L., Christiansen, K. \& Holman, R.T. (1968) The preferred metabolic pathway from linoleic to arachidonic acid in vitro. Biochimica et biophysica acta, 164, 25.

Moncada, S., Gryglewski, R., Bunting, S. \& Vane, J.R. (1976) An enzyme isolated from artery transforms prostaglandin endoperoxides to an unstable substance that inhibits platelet aggregation. Nature. London, 263, 663.

PikaAR, N.A. \& Fernandes, J. (1966) Influence on different types of dietary fat on the fatty acid composition of some serum lipid fractions in infants and children. American Journal of Clinical Nutrition, 19, 194.

SANDERS, A.J. \& NAISMITH, D.J. (1976) Long chain polyunsaturated fatty acids in the erythrocyte lipids of breastfed and bottle-fed infants. Proceedings of the Nutrition Society, 35, 63.

Sinclair, A.J. \& Crawford, M.A. (1973) The effect of low fat maternal diet on neonatal rats. British Journo of Nutrition, 29, 127.

VAN DORP, D.A., BeERThuis, R.K., Nugteren, D.H. VONKEMAN, H. (1964) The biosynthesis of prostaglandins. Biochimica et biophysica acta, 90, 204.

WHO EXPERT COMMITTEE (1964) Nutrition in pregnancy and lactation. Technical Report Series, No. 302. World Health Organization, Geneva.

Willis, A.L., Comai, K., Kuhn, D.C. \& Pausrud, J. (1974) Dihomo- $\gamma$-linolenate suppresses platelet aggregation when administered in vitro or in vivo. Prostaglandins, 8, 509.

Willis, A.L. \& Stone, K.J. (1974) In: Handbook of Biochemistry and Molecular Biology. (Edited by Fasman, C.D.), Vol. 2, 3rd Edn, p. 312. CRC Press, Cleveland, Ohio. 